\title{
Electron Multiple, Plural, and Single Scattering
}

Joseph J. Devaney

\section{DISCLAIMER}

This report was prepared as an account of work sponsored by an agency of the United States Government. Neither the United States Government nor any agency thereof, nor any of their employees, makes any warranty, express or implied, or assumes any legal liability or responsibility for the accuracy, completeness, or usefulness of any information, apparatus, product, or process disclosed, or represents that its use would not infringe privately owned rights. Reference herein to any specific commercial product, process, or service by trante name, trademark, manufacturer, or otherwise does not necessarily constitute or imply its endorsement, recommendution, or favoring by the United States Government or any agency thereof. The views and opinions of authors expressed herein do not necessarily state or reflect those of the United States Government or any agency thereof.
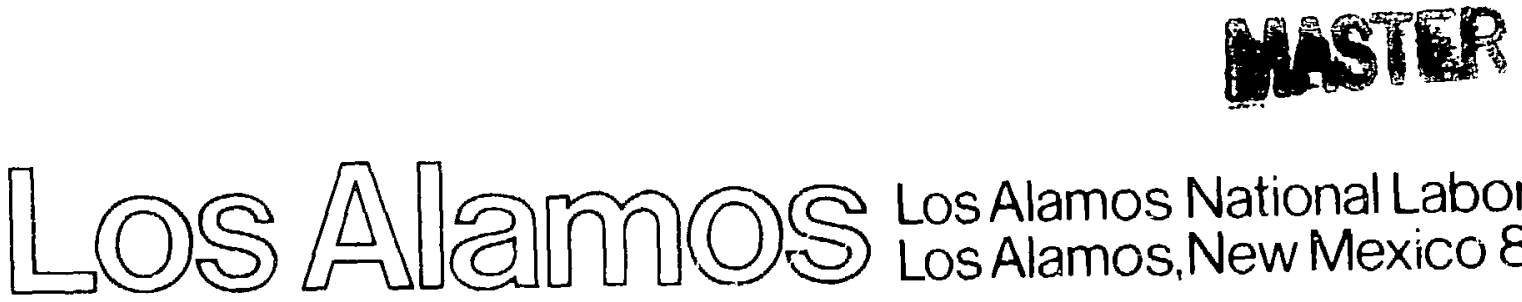

Los Alamos National Laboratory
Los Alamos,New Mexico 87545

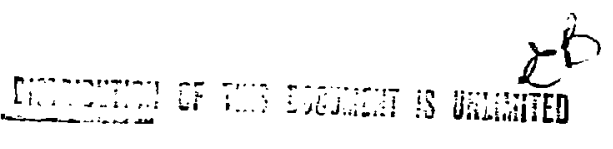




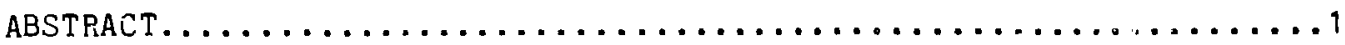

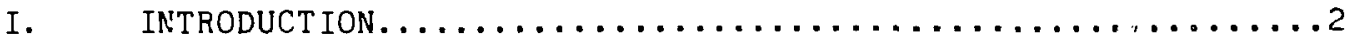

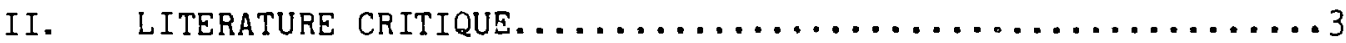

III. HANSON, LANZL, LYMAN, SCOTT, BET̃HE, AND MOLIÉRE THEORY....5

IV. HANSON, LANZL, LYMAN, AND SCOTT APPROXIMATE THEORY.......11

V. MODIFICATIONS OF THE HANSON, LANZL, LYMAN, AND SCOTT APPROXIMATE THEORY............................ 14

VI COMPARISONS WITH EXPERIMENT $\ldots \ldots \ldots \ldots \ldots \ldots \ldots \ldots \ldots \ldots \ldots \ldots$

VII. CONCLUSIONS, RECOMMENDATIONS.......................

VIII. FUTURE NEEDS. . . . . . . . . . . . . . . . . . . . . . 39

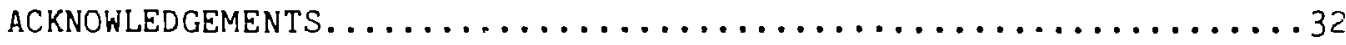

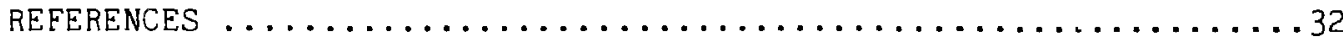

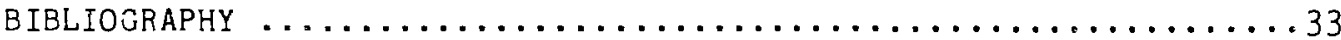




\title{
BLECTRON MULTIPLE, PLURAL, AND SIMGLE SCATTERIKG*
}

\author{
by \\ Joseph J. Devaney
}

ABSTRACT

The angular distribution of a beam of electrons penetrating an infinlte slab is studied with a view to providing simple accurate formulae for use in electron transport codes. We report success, but a righly disappointing success, for although the literature is vast, (over 150 papers), the experiments are limited, sparse, and often poorly described. The theory suffers from complexity, from incomplete, erroneous, or even absent comparisons with other theories and with experiment. Consequently, we carinot say with any assurance what the best theory is, nor to any great accuracy, especially in limiting cases, how good the theory we recommend is. We do give comparisons with the experiments known to us.

With that caveat, we recommend the theory of Molière as given by Bethe and by Hanson et al. Formulas are given. We expect accuracies of a few percent for multiple scattering. For the (in the cases studied) less dominant concomitant plural and single scattering the theory cannot do bet: $2 r$ than 10 to $30 \%$. Because of the complexity of the funciions, either series or tables must be employed.

A bright spot in this somewhat gloomy state of affairs is the calculation of the $1 / e$ width which can be done accurately $(\leq 2 \%)$ by a simple approximation due to Hanson et al.

Using theories of Hanson et al and variants thereof, an approximate "Gaussian" gives a good (7-20\% error) simple description of the multiple scattering. Approximate single scattering formulas are also offered.

*For a brief overview of this paper, we suggest reading the Introduction, Section I, and then the Conclusions and Recommendations, Section VII. 
In attacking the protlem of electron transport, it is of fundamental advantage* to know the anguJar dispersion of a beam of electrons as it passes through matter. The problem is difficult for a number of reasons. To the ordinary difficulty of calculating scattering from Coulomb fields is added the difficulty and uncertainty of atomic electron shielding of such fields. Unless the matter traversed is both very thin and not wide, the scattering is greater than single so that the probabilistic treatment of many scatterings is involved. Although large angle scattering is rare and (multiple) small angle scattering probable, for a full description one must treat simultaneously: single, a few (plural), and many (multiple) scattering of a team of electrons. Last, the algebra involved is complicated and the experiments are difficult.

Usually, in fact nearly universally, the theories treat the scattering in the small angle approximation, $1.2 . \sin \theta, \tan \theta \rightarrow \theta$. The Thomas-Fermi statistical atom is used to estimate shielding. In order to make the formidable algebra tractable, further mathematical approxinations are usually introduced. Enormous effort has been expended on the problem. Some 150 papers are referenced by $w$. T. Scot.t in his 1963 review article. 1 The bench-mark theory is without doubt that of Molière.2 A clearer, simpler exposition of Moliare's theory is to be found in Bethe's work.3 A key advantage to the Molière theory is that it gives not only the "Gaussian" central multiple scattering but also the transition through plural to single scattering as the angle of scattering increases. As a consequence, experimentalists universally test their results against the Molière theory. "Good agreement has usually been obtained." 4 We substantiate that remark. See Tables III to VI. For those reasons we recommend and will provide formulas below for the Molière theory. However, because authors have concentrated on the 1/e width of the distributions which have frequently been claimed to be accurate to about a percent, some have missed the fact that the rest of the distribution can have even an order of magnitude greater error as we will show below. Moreover, there is contention among theories and uncertainty in the experiments that lead to considerable lack of confidence in any results. Thus, in zddition to

*Information supplied by Joseph Mack, $X-6$, and Buck Thompson, $x-6$ Group Leader. 
the inconvenience of the complex algebra of Iull theories, like Molière's, the accuracy therenf may only be of modest. improvement over a simpler theory in the dominant central scaitering region. For the central multiple scattering, the Hanson et al 5 Caussian approximation does as well as the Molière theory in giving the $1 / \mathrm{e}$ width 5,6 (Table III), and for the distribution function is possibly as good as at least some experimental error for angles less than the $1 / \mathrm{e}$ angle. However, the approximation does not give the less probable plural scattering at ali. In Hanson's paper5, Molière matches experiment well except at about 3 times the $1 / \mathrm{e}$ angle where the theory is as much as $30 \%$ low. However, this large angle scattering is at a scattered intensity of only - 1/1000 of the peak at no scattering angle and is nearly in the single scattering region 5 .

In the noxt section wo give $a$ brief critique of the literature. Then we give formulas for the Molierre-Bethe-Hanson theory which is recommended as the practical best, but with reservations. Then we give the Hanson approximate theory with both a central "Gaussian" and a single scattering part. This approximation, or our variant thereof, may well be the optimum presently for calculations. It is far and away the simplest. We give modifications to the Hanson et a: approximation. We give what experimental comparisons we can find. We summarize and give ronommentatiors and finish with a plea for further research.

\section{LITERATURE CRITIQUE}

In the opinion of this witer the literature on (multiple) electron scattering is disappointing in that much difficult, innovative work $1:$ s been done, but very frequently indeed: results are not stated; results, if stated, are not rendered in readily useable form; previous wor's is not compared, nor is theoretical work compared with experiment. For example, a new theory may be proposed but no evidence is given that it is in fact better than previous theories. Often, when comparisons are made, they are made only among $1 / e$ widths. Some experimental results are only relative, leaving the reader to 
attempt numerical integration with only small graphs ?vailable. Sometimes only projected (on a plane containing the initial eleccron beam) distributions are given. Particular comments follow.

Scott ${ }^{1}$ repeats the derivations of many theories up to about 1961 or so, explaining and improving the methods, but recommends no best theory, nor any best approximate theory. A great pity, because scott has, at, great effort ploughed through the different theories with great care and in enormous detail. He is quite likely the most knowledgeable of their comparative merits. He makes some comparison with experiment, e.g. with Hanson et al, 5 but only compares the widths.

The early work of Gcudsmit and Saunderson 7 (1940) al leges an exact theory valid to all angles, but the theory is given in terms of particle path length which is effectively of little accurate ure except for small angles. Further, E. Breitenberger argues ${ }^{8}$ that one of their hidden assumptions is good orly for small angles. See also Molière.?

Nigam, Sundaresar, and Wu allege 9 that Moljère uses an inconsistent approximation to all orders in the parameter $\alpha \equiv \angle Z / 937 B$. ( $z$ 's are chargo numbers, $B$ is electron velocity divided by light velocity, $v / c)$. However, Molière generally agrees with experiment, see Section VI, but Nigam et al require an adjustable parameter (for atomic screening differences) which for $\mathrm{Au}$ and Be amounts to 1.8, (Ref. 9). Because this parameter is not derived by theory (although it can be) and checked by experiment, ic must be regarded as somewhat ad hoc and is a whopping $80 \%$ correction.

Experimental error may be larger thin the error bars given. For examPie in Kulchitsky and Latyshev ${ }^{10}$, left to right scattering cross-sections or intensities differ by $14 \%$ at $10.9^{\circ}$ and $50 \%$ at $32.6^{\circ}$ for $0.0174 \mathrm{~g} / \mathrm{cm}^{2}$ of $\mathrm{Sn}$, and by $8 \%$ at $8^{\circ}$ and $35 \%$ at $16.2^{\circ}$ for $0.0079 \mathrm{~g} / \mathrm{cm}^{2}$ of $\mathrm{Fb}$, both for $2.25 \mathrm{MeV}$ incident electrons. In contrast their error bars are of the order of $\pm 3 \%$ or less. Kulchitsky and Latyshev give relative distributions only. Their $1 / e$ values are $10.65^{\circ}$ for $S n$ and $9.70^{\circ}$ for $P b$. 
Nearly all the theories restrict themselves to small angles, i.e. such that $\sin \theta-\theta$ or say for $\theta \leq 30^{\circ}$. However, the naive view that large angle scattering is single and thus adequately given by Rutherford's (or Mott's = relativistic) formula is only correct on the smaller angle end when plural scattering is negligible, and on the larger angle end when the electron energy and scattering angle are low enough that the electron wave function does not sample the nuclear fields significantly and also when the large angle is not so large that the probability of multiple scattering in the target slab after the single-large-angle-scattering is not large. This last restriction applies to the thinnest target. See the interesting work of J. H. Jacob.11

J. H. Jacob ${ }^{11}$ alleges an exact electron scattering theory (for constant electron energy) and for any angles. Tra resuits require truncation of an infinite matrix expansion and so are likely beyond the present anticipated practical use of $X-D i v i s i o n$. In addition there is nearly zero comparison with experiment, primarily because there is no experiment at the large angles. Indeed we need high quality experiment for all angles. The theory does match earlier theories which in turn match Hanson et al. However, Jacob's interesting work certainly deserves further study.

\section{HANSON, LANZL, LYMAN, SCOTT, BETHE, AND MOLIÈRE THEORY}

This seciion gives the Molière Theory ${ }^{2}$ as presented by Bethe 3 and by Hanson et a1.5 It is, as given here, supposed to be good to a percent or better, 3 but I cannot demonetrate that eccuracy against experiment5,6,10 (see Tables IV, $V$, and $V I$ ), except for the 1/e widths, (Table III). The $1 \%$ accuracy quct?d 3 apparently refers also to the accuracy of the Bethe-Molière Theory's first three terms relative to the full sum, but other errurs arjsing from the approximate treatment of Bethe-Molière could be significant. Use of the Thomas-Fermi Statistical Atom comes to mind 3,5,9 But see Ref. 14 for a contrary finding. We will compare the three te m Hanson et al, Bethe, Molière theory, wich we call HBM icr convenience, with experiment below (Tables III to VI). Unfortunately the number of experimental studies is low, and their utility lower yet, as described in the preceding section. Nonetheless the 
Molière theory appears by far to be the most tested against experiment with good agreement generally found. $5,6,10,12-14$ The tests do not include very thin foils nor very thick foils. In the former, however, the theory does possess the proper limit, to wit a $\delta$-function for the distribution, (and Rutherford single scattering for thin slabs). For the latter the limit of the theory to small angle scattering effectively restricts the slab thickness relative to the electron velocities. For electron energies and slab thicknesses that limit the beam broadening to an experimentally convenient 10 degrees or so, experiment has tested the theory from $1.66 \mathrm{MeV}^{12}$ through 2.25 $\mathrm{MeV}^{10}, 4.5 \mathrm{MeV}^{6}$, and $15.7 \mathrm{MeV}^{5}$, to $600 \mathrm{MeV}^{14}$ (at $600 \mathrm{MeV}$ the scattering angles are only $\left.\leq-0.01^{\circ}\right)$.

The HBM theory presented below has the following limitations:

1. To small scattering angles, i.e. such that $\sin \theta-\theta$, or say for angles $\theta \leqslant 30^{\circ}$, (difference of $\theta$ to $\sin \theta$ at $30^{\circ}$ is $+4.7 \%$ ).

2. No spin correctiors. These and relativistic corrections are only appreciable for large angle single scattering. 3

3. The sole relativistic correction is found in the formula:

$$
p^{2} v^{2}=\left(2 m_{0} c^{2} k+k^{2}\right) B^{2}
$$

where $p$ is momentum, $v$ velocity, $B \equiv v / c, c$ is the velocity of light, $m_{0}$ the rest mass of the electron, and $k$ the electron kinetic energy.

4. The Thomas-Fermi statistical atom is used. Some erratic results may therefore be expected for low $Z$, (Ref. 5), but see the results of Mohr and Tassie given in Ref. 14 for a contrary view.

5. No effects of electron energy loss are included. For slabs not too thick, the mean energy in the foil should be used. For very thick slabs, but not violating limitation 1 above, integration is required. 
6. No nuclear effects are included; i.e. we assume a point nucleus. (Nuclear size and reactivity affect most the large angle, low $\mathrm{Z}$, high electron energy scattering).

7. Atom lucation is randon, i.e., no collective effects.

8. Electron beam intensity is sufficiently low (and energy sufficiently high) that self repulsion of the electrons is negligible in angle.

9. The additional effect of the atomic electrons on the electron scattering is adequately approximated by replacing one $Z$ by $(Z+1)$ in the scattering term.

10. Neither the density of atoms nor the electron beam density is so great that the Pauli Exclusion Principle must be invoked.

11. Some integrals are evaluated approximately.2,3

This list of limitations is not by any means impossibly restrictive. Of the few experimenis we possess, the theory fits the multiple, plural, and single scattering from well to fair, possibly to within realistic experimental error, or at least close to that. It is impossible to say precisely how good the fits are because the data itself are often given without errors.

Because no polarizations or other azimuthal asymmetries are treated there is no manifest azimuthal angular dependence. The normalized differential cross-scotion for a slab is then written: 3

$$
\begin{gathered}
2 \pi \frac{d}{d \Omega} \theta d \theta \equiv f(\theta) \theta d \theta=w^{-2} \theta d \theta\left[f^{(0)}\left(\theta^{2} / w^{2}\right)+B^{-1} f^{(1)}\left(\theta^{2} / w^{2}\right)+\right. \\
\left.B^{-2} f^{(2)}\left(\theta^{2} / w^{2}\right)\right]
\end{gathered}
$$


where $f(\theta)$ is the angular distribution function in the scattering angle $\theta$, (no $\Phi$ dependence), with the normalization, 3

$$
\delta^{\infty} f(\theta) \theta d \theta=1
$$

Note that our solid angle $d \Omega=2 \pi \theta d \theta$ since $\sin \theta \rightarrow \theta$ and we have azimuthal symmetry. $\sum$ is the psuedo cross-section of the entire slab. $w$ is a width, the "Gaussian" width of the first term, $f(0)$.

$$
w \equiv x_{C} B^{1 / 2}
$$

We define a unit probability scattering angle, $x_{c}$, as

$$
x_{c}^{2} \equiv \frac{4 \pi \sigma N_{a} Z(Z+1) e^{4} z^{2}}{A(p c)^{2} B^{2}}
$$

where

$$
(p c)^{2}=K^{2}+2 m_{c} c^{2} k
$$

and

$$
B^{2}=1-i 1+\frac{K}{m_{0} c^{2}} j^{-2}
$$


(It turns out that differing values for the constants in Lq. (5) can lead to - 1\% differences in $x_{c}$ which.in turn leads to yet greater difrerences in the distribution functions, $\left.f_{.}\right) \sigma$ is the slab thickness in $\mathrm{g} / \mathrm{cm}^{2}, N_{a}$ is Avogidro's number, $\mathrm{Z}$ the charge number of the target atoms, $\mathrm{e}$ the electron charge, $\mathrm{z}$ the charge number of the projectiles. For electrons, $z=-1$. A is the atomic weight of the target, pc the projectile momentum in energy units, $B=v / c$ the ratio of projectile velocity to light velocity, $K$ is the projectile kinetic energy, and $m_{0} c^{2}$ the projectile rest mass. The quantity $x_{c}^{2} / \theta^{2}$ is the relative probability of having a single scattering of angle greater than $\theta$ in the foil; thus the relative probability of having a scattering greater than the angle $x_{c}$ is exactly 1 (Ref. 3). $x_{c}$ is a measure of the effective foll thickness. The Molière characteristic scattering angle $x_{a}$ is given by:

$$
x_{a}^{?}=\left[\frac{k z^{1 / 3} c}{0.885 p c a}\right]_{0}^{2} \cdot\left[1.13+3.76\left(\frac{z}{1378}\right)^{2}\right]
$$

$h$ is Planck's constant divided by $2 \pi, a_{0}=h^{2} / m_{O} c^{2}$ is Bohr's atomic radius. $B$ is given by:

$$
B=\ln B+\ln \left[6 x_{c}^{2} / 7 x_{a}^{2}\right]
$$

which is readily solved by a few iterations starting with a guess :or $B_{0}$ (say try $8 \mathrm{for} 1 / \mathrm{e}$ scattering of - 100):

$$
B_{n}=\ln B_{n-1}+\ln \left[5 x_{c}^{2} / 7 x_{a}^{2}\right] .
$$


The characteristic scattering angle, $\chi_{a}$, is the prime descriptor in the theory of the details of the scattering atom, $1 . e$, the target atom. It, together with $x_{c}$, completely gives the whole scattering theory. Defining:

$$
x \equiv(\theta / w)^{2}=\theta^{2} / x_{c}^{2} B
$$

the functions $\mathrm{f}^{(i)}$ of Eq. (2) are: 3 the "Gaussian" (becalise $x=\theta^{2} / \mathrm{w}^{2}$ ):

$$
\begin{gathered}
f^{(u)}=2 e^{-x}, \\
f^{(1)}=2 e^{-x}(x-1)\left[\gamma+\sum_{n=1}^{\infty} \frac{x^{n}}{n \cdot n !}\right]-2\left(1-2 e^{-x}\right)
\end{gathered}
$$

where $\gamma=0.5772156649$ is Euler's constant, and

$$
\begin{aligned}
f^{(2)}= & e^{-x}\left\{1.246465014\left(x^{2}-4 x+2\right)+4 \sum_{n=0}^{\infty} \frac{1}{n+1}\left[0+1+\frac{1}{2}+\frac{1}{3} \cdots\right.\right. \\
& \left.\left.+\frac{1}{n}-0.922784345\right] \cdot\left[\frac{x^{n+3}}{(n+3) !}-\frac{2 x^{n+2}}{(n+2) !}+\frac{x^{n+1}}{(n+1) !}\right]\right\}
\end{aligned}
$$

Note: a factor of $1 / 4$ is missing from the first term of Bethe's expression (29), Ref. 3., for $\mathrm{f}^{(2)}$. Bethe's $\mathrm{f}^{(2)}$ in Table II, Ref. 3, is however correct, but not his $(1 / 2) \mathcal{V}^{4} \mathrm{f}(2)$ first two entries. See my Table I. See Molière, second paper Ref. 2, D, 9, p. 96. 
For small angles, $\mathrm{f}^{(0)}$ is the dominant term; it describes inultiple scattering. $\quad f^{(1)}$ and $f^{(2)}$ give plurai and single scattering. In fact for $n \geq$ 1 (Ref. 3).

$$
\mathrm{f}^{(n)} \underset{\theta \rightarrow \infty}{\longrightarrow} \text { constant } \cdot \theta^{-2 n-2}
$$

so that $\mathrm{f}^{(1)}$ goes over into the single snattering (Rutherford) law

$$
f_{\theta \rightarrow \infty}^{(1)} \propto \theta^{-4} \text {, (in fact } f^{(i)}=2 w^{4} / \theta^{4} \text { in the Iimit). }
$$

$f(0)$ by itself is a fair approximetion, but a (usually) better "Gaussian" approximation is found in section IV and $V$ next. $\mathrm{f}^{(0)}+\mathrm{B}^{-1} \mathrm{f}^{(1)}$ is a good approximation and the three term $\mathrm{f}^{(0)}+\mathrm{B}^{-1} \mathrm{f}^{(1)}+\mathrm{B}^{-2} \mathrm{f}^{(2)}$ is expected to be a very good approximation within the limitations abo ? to the angular distribution function. However, as I ncted above, J cannot demonstrate the high accuracies claimed 3 against experiment. See below, Section VI.

Table I is derived from Bethe's Table II (Ref. 3) giving values for the functions $f^{(0)}, f^{(1)}, f^{(2)}$. His

$$
\mathscr{Y} \equiv \theta / \mathrm{w}
$$

in the Table. The last two columns are more suitable for interpolation (for $(\theta / w) \geq 1)$ than columns 3 and 4 . Entries two and three in Col. 5 were in error, as noted.

\section{HANSON, LANZL, LYMAN, AND SCOTT APPROXIMATE THEORY}

This section gives the Hanson et al 5 approximate theory which we shall for brevity sall the Hanson or $H$ theory. The HBM theory given above treats not only multiple scattering, but also plural and single scattering. The 
TABLE I

Values of the $r(1)$ Functions

(after Bethe 3 Table II)

\begin{tabular}{|c|c|c|c|c|c|}
\hline $\mathscr{N}$ & $r(0)$ & $r^{(1)}$ & $r^{(2)}$ & $(1,2) V^{h} r^{(1)}$ & $(1 / 2) \boldsymbol{N}^{b}{ }^{\prime}(2)$ \\
\hline $\begin{array}{l}0 \\
0.2 \\
0.4 \\
0.6 \\
0.8\end{array}$ & $\begin{array}{l}2 \\
1.9216 \\
1.7214 \\
1.4094 \\
1.0546\end{array}$ & $\begin{array}{r}0.8456 \\
0.7038 \\
0.5137 \\
-0.0777 \\
-0.3981\end{array}$ & $\begin{array}{r}2.4929 \\
2.0694 \\
1.04 R 8 \\
-0.0044 \\
-0.6068\end{array}$ & $\begin{array}{r}0 \\
0.0006 \\
0.0044 \\
-0.0050 \\
-0.0815\end{array}$ & $\begin{array}{l}G \\
0.00166(\text { Eethe: } 0.0000) \\
0.01343(\text { Bethe: } 0.0034) \\
-0.00285(\text { Bethe: }-0.003) \\
-0.1246\end{array}$ \\
\hline $\begin{array}{l}1 \\
1.2 \\
1.4 \\
1.6 \\
1.8\end{array}$ & $\begin{array}{l}0.7338 \\
0.4738 \\
0.2817 \\
0.1546 \\
0.0783\end{array}$ & $\begin{array}{l}-0.5285 \\
-0.4770 \\
-0.3183 \\
-0.1396 \\
-0.0005\end{array}$ & $\begin{array}{r}-0.6359 \\
-0.3086 \\
0.0525 \\
0.2423 \\
0.2386\end{array}$ & $\begin{array}{l}-0.2642 \\
-0.4946 \\
-0.6113 \\
-0.4573 \\
-0.0032\end{array}$ & $\begin{array}{r}-0.318 \\
-0.320 \\
0.101 \\
0.669 \\
1.251\end{array}$ \\
\hline $\begin{array}{l}2 \\
2.2 \\
2.4 \\
2.5 \\
2.8\end{array}$ & $\begin{array}{l}0.0366 \\
0.01581 \\
0.00630 \\
0.00232 \\
0.06079\end{array}$ & $\begin{array}{r}+0.0742 \\
0.1054 \\
0.1008 \\
0.08262 \\
0.06247\end{array}$ & $\begin{array}{r}0.1316 \\
0.0196 \\
-0.0467 \\
-0.0649 \\
-0.0546\end{array}$ & $\begin{array}{l}0.6258 \\
1.2347 \\
1.6718 \\
1.8877 \\
1.9200\end{array}$ & $\begin{array}{r}1.053 \\
0.475 \\
-0.775 \\
-1.483 \\
-1.676\end{array}$ \\
\hline $\begin{array}{l}3 \\
3.2 \\
3.4 \\
3.6 \\
3.8\end{array}$ & $\begin{array}{l}0.000250 \\
7.3 \times 10^{-5} \\
1.9 \times 10^{-5} \\
4.7 \times 10^{-6} \\
1.1 \times 10^{-6}\end{array}$ & $\begin{array}{l}0.04550 \\
0.02>88 \\
0.02402 \\
0.01791 \\
0.01366\end{array}$ & $\begin{array}{r}-0.03568 \\
-0.01913 \\
-0.00847 \\
-0.00264 \\
0.00005\end{array}$ & $\begin{array}{l}1.3429 \\
1.7240 \\
1.6050 \\
0.5038 \\
1.4237\end{array}$ & $\begin{array}{r}-1.448 \\
-1.008 \\
-0.566 \\
-0.222 \\
0.005\end{array}$ \\
\hline 4 & $\begin{array}{l}1000 \mathrm{f}(0) \\
2.3 \times 10^{-4} \\
3 \times 10^{-6}\end{array}$ & $\begin{array}{l}1000 \mathrm{f}(1) \\
10.638 \\
6.14 \mathrm{C}\end{array}$ & $\begin{array}{l}1000 f(2) \\
1.0741 \\
1.2294\end{array}$ & $\begin{array}{l}1.3617 \\
1.2588\end{array}$ & $\begin{array}{l}0.1375 \\
0.2521\end{array}$ \\
\hline $\begin{array}{l}5 \\
5.5\end{array}$ & $\begin{array}{l}2 \times 10^{-r} \\
2 \times 10^{-10}\end{array}$ & $\begin{array}{l}3.83 i \\
2.527\end{array}$ & $\begin{array}{l}0.8326 \\
0.5368\end{array}$ & $\begin{array}{l}1.1972 \\
? .1563\end{array}$ & $\begin{array}{l}0.2602 \\
0.2456\end{array}$ \\
\hline 6 & $5 \times 10^{-13}$ & 1.739 & 0.3495 & 1.1275 & 0.2264 \\
\hline 7 & $1 \times 10^{-18}$ & 0.9080 & 0.1584 & 1.0901 & 0.1901 \\
\hline 8 & $3 \times 10^{-25}$ & 0.5211 & 0.0783 & 1.0679 & 0.1604 \\
\hline 9 & $1 \times 10^{-32}$ & 0.3208 & 0.0417 & 1.0523 & 0.1363 \\
\hline 10 & $1 \times 10^{-40}$ & 0.2084 & 0.0237 & 1.0419 & 0.1186 \\
\hline
\end{tabular}


"Gaussian," $f(0)$, of that theory gives the dominant multiple scattering term, except for slabs so thick that the sin $\theta \rightarrow \theta$ approximation is itsclf violated so invalidating the HBM theory. This Gaussian alone is sufficient to describe well the dominant multiple scattering part. However, by a smali correction, Hanson et al 5 rlade the Gaussian generally better, in fact just as good as the rull theory as far as the $1 / \mathrm{e}$ width is concerned. So, unless one is interested also in the low probability, wider angle scattering in the wings of the distribution, the Hanson theory is a relatively good approximation. Its simplicity is great, for it omits entirely the complicated expressions for $f(1)$ (Eq. (13)) and $f(2)$ (Eq. (14)).

The Hanson distribution, $f_{H}$, is

$$
\mathrm{r}_{H}=2 \pi \mathrm{d} \Sigma_{H} / \mathrm{d} \Omega=\left(2 / w_{H}^{2} j \cdot \mathrm{e}^{-\left(\theta^{2} / w_{H}^{2}\right)}\right.
$$

with usual normalization:

$$
\oint^{\infty} \mathrm{f}_{H} \theta \mathrm{d} \theta=1
$$

where

$$
w_{H} \equiv x_{C}(B-1 \cdot 2)^{1 / 2}
$$

Eqs. (18) and (20) give the central, dominant, multiple scattering part of a beam divergence. $x_{C}$ is obtained from Eq. (15), and B from Eq. (9) or (10). For large angles (but $\leqslant 30^{\circ}$ so that $\sin \theta=\theta$ ) where single scattering will dominate, (i.e. $2 w_{\mathrm{H}}$ also $<25^{\circ}$ so that multiple and plural scattering do 
not dominate the scattering), Hanson et $a{ }^{5}$ give a good rule of thumb for the scattering distrioution:

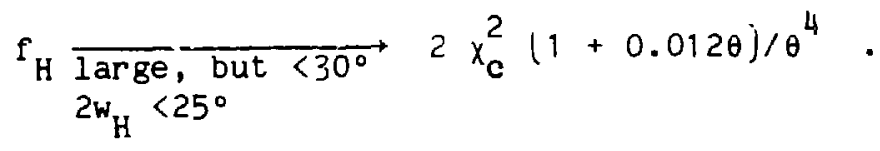

Eqs. (18) and (21) do a fair job of the entire distribution if one uses Eq. (18) up to $\theta=1.8 \mathrm{w}$ and then Eq. (21) beyond. Plural scattering is not included so the scattering at about $2 w_{H}$ to $4 w_{H}$ cannot be expected to be well represented and 30 it proves. Maximum errors of - 65\% are round comparing Eq. (21) to Hanson et al 5 experiments. Note that in Hanson et al 5 the Gaussian displayed is not that of Hanson's widtr. $w_{H}$ (our Eq. (20), but rather of Molière's width w (our Eq. (4)). The Moliere Gaussian being wider, matches experiment better in the plural range and so should be used optimally out to $\theta$ $=2.5 \mathrm{w}$ before using Eq. (21). This procedure leads to lower maximum errors compared with the Hanoun et al data in ths plural range, but usually to higher errors in the dominant, small angle, multiple scattering regime than the Hanson approximation. Note also that plural scattering typically 5 begins to be important when the multiple scattering has dropped in intensity by more than an order of magnitude. So that the foregoing errors occur in a very small, usually negligible (if larger angle scattering per se is not important) part of the total distribution. In the riext section we discuss possible improvements to Hanson's approximation.

\section{v. MODIFICATIORS OF THE HANSOH, LANZL, LMAN, AND SCOTT APPROXIMATE THEORY}

Some simple modifications of the Hanson et al theory ${ }^{5}$ give better agreement with selected theory in selected energy regions. This section gives two such modifications. They are specialized improvements and are only slightly, if at all, superior in general to the Hanson et al approximation. They are inferior in some aspects, for example the 1/e width. Were there a 
good and more complete "corpus experiment," one might expect to make general improvements. But there isn't. So rurther effort cannot be proved to be super or. We will restrict oursulves to the Hanson et al data to calculate the modifications given in this section and then compare with other experiments as well in the next section.

\section{Modification $Y$}

This is a normalized "Gaussian" matcned to experiment at zero scattering angle, $\theta=0$. Because the multiple scatteriug probability distribution peaks at zero scattering ang?.e, it can be argued, on the basis that any approximation should fit the highest prcbability best, that one should match experiment at zero scattering angle. (In contrast the $H$ approximation fits the angular spread best, i.e. at $1 / \mathrm{e}$ ).

The Mod. I distribution is:

$$
2 \pi \frac{d I_{I}}{d \Omega}=f_{I}=\left(2 / w_{I}^{2}\right) e^{--\left(\theta^{2} / w_{I}{ }^{2}\right)}
$$

with usizl normalization:

$$
\delta^{\infty} f_{I} \theta d \theta=1
$$

$w_{I}$ is now determined from matching the normalized experiment, $f(0)$ experiment at $\theta=0$.

$$
W_{I}=\sqrt{2 / f_{\text {experiment }}^{(0)}}=1 / \sqrt{\left.\pi \frac{\mathrm{a} \Sigma}{\mathrm{d} \Omega}\right|_{\theta} \text { experiment }_{=}}
$$


At $15.7 \mathrm{MeV}$ electrons incident, we gti the values given in Table II. We will compare these widths with others in Table III.

Where $x$ is defined:

$$
w_{I} \equiv x_{c} \sqrt{B-x}
$$

with the unit scattering angle $x_{c}$ given by Eq. (5) and B by Eq. (9) or (10). For the Hanson et al approximation of Section IV, $x=1.2$. The departure of $x$ in Table II from 1.2 is an indication of the inexactness of the Hanson Approximation in fitting $f(\theta=0)$. More anon, (Tables IV, $V$, and $V I)$. The parameter $x$ of Table II is precisely fit by:

$$
x=0.579+1.130+(-0.386+9.08 \sigma) \cdot\left(\frac{z-4}{75}\right)
$$

where $\sigma$ is the target thickness in $\mathrm{g} / \mathrm{cm}^{2}$ and $z$ is the target atomic number. Mod. I approximation is given by Eqs. (24), (25), and (22). Its accuracy will be tested in the next section. Of course, by construction, $x$ determined by Eq. (26) gives a perfect fit to the cour Hanson et al 5 experimental distributions at $\theta=0^{\circ}$. In the absence of experiment at $\theta=0^{\circ}$, Eq. (24) cannot be used. Mod. I* approximation, now designated by an asterisk, will then be given by Eqs. (26), (25), and (22).

\section{Modiflcation II}

One can improve Hanson's large angle approximation, Eq. (21), both to fit his Au data better, (he does not give large angle data for $B e$, so we cannot be sure that Mod. II is better also for $B e$ ), and to be more accurate for Q2 $30^{\circ}$. We remind the reader that for net scattering angles near $90^{\circ}$ the 
TABLE II

\section{BAMSON, LANZL, LYMAN, AND SCOTT MODIFICATION I PARAMETERS \\ (Incldent Electron Energy = $15.7 \mathrm{MeV}$ )}

\begin{tabular}{|c|c|c|c|c|}
\hline Element & $\mathrm{Be}$ & $\mathrm{Be}$ & $\mathrm{Au}$ & $\mathrm{Au}$ \\
\hline Target Thickness $\left(\mathrm{g} / \mathrm{cm}^{2}\right)$ & 0.257 & 0.4913 & 0.01866 & 0.03728 \\
\hline $\begin{array}{c}\frac{d}{d \Omega} \mid=\text { iperiment, } \theta=0 \\
\operatorname{deg}^{-2}(\text { pef. } 5)\end{array}$ & 0.0317 & 0.0153 & 0.0441 & 0.0200 \\
\hline${ }^{W} I$ & $3.17^{\circ}$ & $4.56^{\circ}$ & $2.69^{\circ}$ & $3.99^{\circ}$ \\
\hline$x$ & 0.868 & 1.132 & 0.383 & 0.574 \\
\hline
\end{tabular}


scattering is not Rutherford even for thin slabs. 11 The reason is that a scattering by about $90^{\circ}$ forces the particle then to travel thrcugh a much greater amount of material than the slab thickness with the consequent near certainty of subsequent (multiple) scattering leading to large departures from the Rutherford (or Mott) law. 11

Each of Hanson's Au curves can be fitted separately and a thickness dependent parameter set developed, but, for simplicity, we leave all the thickness dependence in the parameter $x_{C}$ of $E q$. (5) to give:

$2 \pi \frac{d \Sigma_{I I}}{\sin \theta d \theta d \phi}=f_{I I}(\theta)=0.9028 \cdot 2 \pi \cdot x_{c}^{2} \cdot(1-1.0093 \sin \theta) /(\sin \theta)^{4}$

which does a little better than Hanson's Approximation. Eq. (21), to wit a maximum error of $-35 \%$ (for Au) versus - 65\%, plus lower errors ( 0 to 17\%) near 2w (where the "Gaussian" fails) and lower errors $(\rightarrow 0 \%)$ in the large angle limit, except near $90^{\circ}$ as noted above.

\section{COMPARISONS WITH EXPERIMENT}

In this section we compare the Hanson-Bethe-Molière (HBM) theory with experiment. We also compare the Hanson et al approximation, as well as our modifications of it, with experiment. As we noted in our critique of the literaturs in section II, authors often give only a comparison of $1 / \mathrm{e}$ widths and not of the whole scattering distribuicion. However, it would be wrong to conclude that such comparisons are totally valueless, they are rather tho very concise reduction of an entire curve to but a single number. That number is, however, the most representative single rumber describing the distributions since they are, for much of the parameter space, dominated by a "Gaussian," i.e. an exponential in $\theta^{2}$.

Table III gives comparisons of $1 / \mathrm{e}$ widths, theoretical to experimental for all cases where I coulc find the parameters given. WHBM is of course the $1 / \mathrm{e}$ width from the Hanson et al, Betre, Molière theory of Section III. Wis 
TABLE III

Comparisons of 1/e widths, $w$, of Electron Bean Broadening Following SLab Penetration

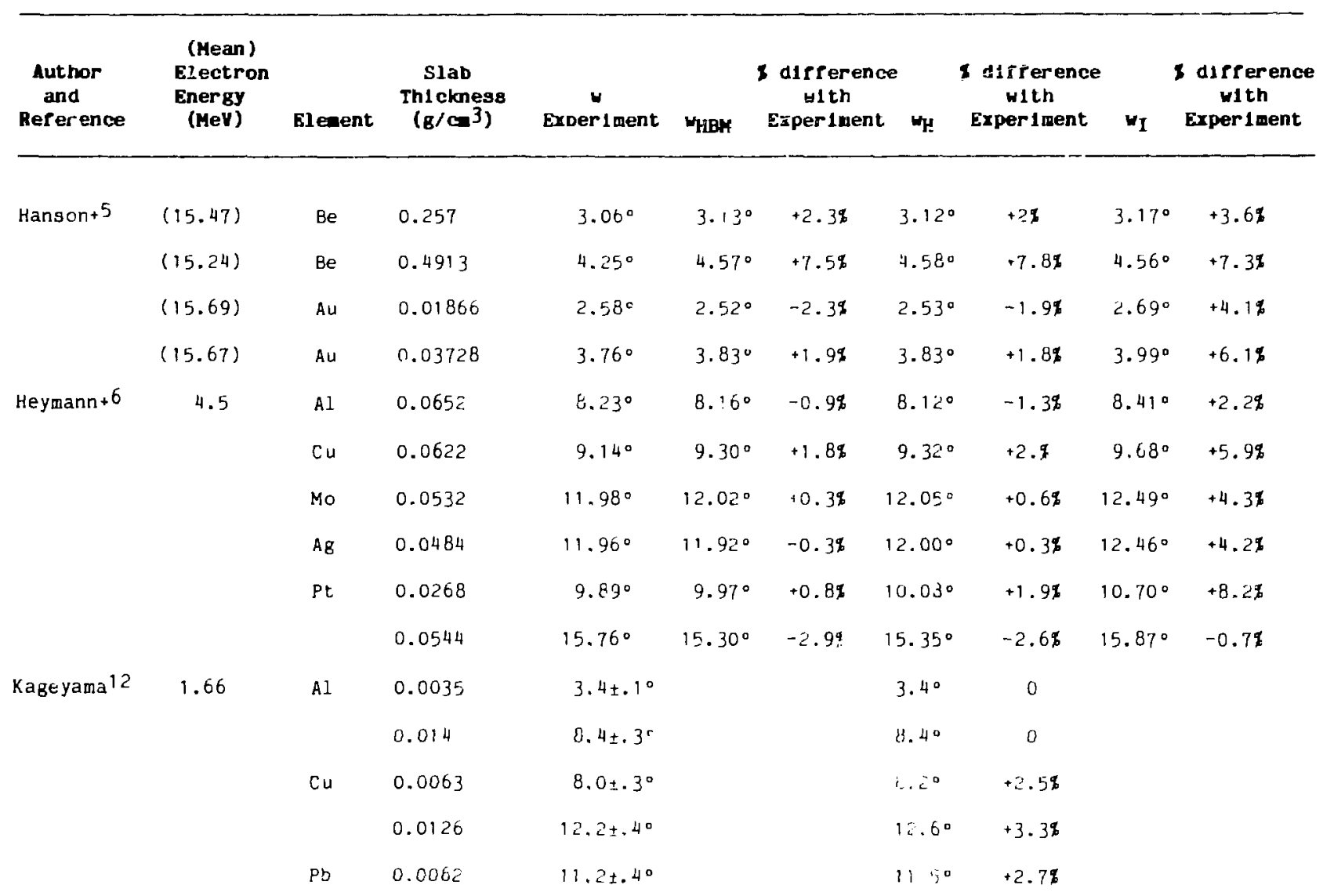


TABLE III (cont)

\begin{tabular}{|c|c|c|c|c|c|c|c|c|c|}
\hline $\begin{array}{l}\text { Author } \\
\text { and } \\
\text { Reference }\end{array}$ & $\begin{array}{l}\text { Electron } \\
\text { Energy } \\
\text { (HeV) }\end{array}$ & Element & $\begin{array}{c}\text { Slab } \\
\text { Thickness } \\
\left(\mathrm{g} / \mathrm{c}^{3}\right)\end{array}$ & $\stackrel{\text { Experiment }}{\text { Ex }}$ & & 8 & $\begin{array}{c}\text { difference } \\
\text { with } \\
\text { Experiaent }\end{array}$ & I & $\begin{array}{c}1 \text { a teference } \\
\text { with } \\
\text { Erf Iment }\end{array}$ \\
\hline \multirow[t]{5}{*}{ Mozley +14} & 600 & $\mathrm{Be}$ & 0.0123 & $0.01371^{\circ}$ & $+2.5 \%$ & $0.0,376^{\circ}$ & +0.38 & & \\
\hline & & $A 1$ & 0.00244 & $0.00849^{\circ}$ & \pm 38 & $0.00859^{\circ}$ & $+1.1 \%$ & & \\
\hline & & & 0.00706 & $0.01708^{\circ}$ & $\pm 3 \%$ & $0.01752^{\circ}$ & $+2.6 \%$ & & \\
\hline & & & 0.0205 & $0.03343^{\circ}$ & $\pm 2.5 \%$ & $0.03411^{\circ}$ & $+2.0 \%$ & & \\
\hline & & $\mathrm{Au}$ & 0.0103 & $0.04636^{\circ}$ & $\pm 3 \%$ & $.0 .04645^{\circ}$ & $+0.2 \%$ & & \\
\hline
\end{tabular}




\section{TABLE IV, A}

Cospari sons with Experiment: Hanson et al 5 for Au, 0.01886 g/ces ${ }^{2}$, Hean Flectron Energy 15.69 MeV $\left(v=2.768^{\circ}\right.$ Eq. (4), B -6.5077 Eq.(9), $x_{c}=1.085^{\circ}$ Eq.(5), $\forall_{H}=2.53^{\circ}$ Eq.(20)

(we use Hanson's $\left.x_{c}-1.10^{\circ}\right), x=0.383$ Eq.(26), $w_{I}=2.69^{\circ}$ Eq. (24).

\section{Paraneter}

$\widetilde{\sigma} \equiv \theta / \mathrm{m}$ Eq. (17)

Scatterlng Angle, 8

$\frac{f(\theta)}{2 \pi}-d \Sigma / d \Omega \mid$ Eq. (2)

$f_{\mathrm{HBM}} / 2 \pi, \mathrm{EQ} \cdot(2)$

$\$$ difference HBM: expt.

$f_{H} / 2 \pi$, Eq. ( 1 g), (Gausstan)

plural

$\mathrm{f}_{\mathrm{H}} / 2 \pi$. Eq. (21), angle) single

d difference, H:expt.

$P \perp$ ural

$f_{I} / 2 \pi, E q .(22)$, (sinall angle)

Gaussian

$f_{I I} / 2 \pi, E q$. (27), (large angle Rutherford

* difference, I : expt.
Dowinant Central $\leftarrow$ "Gaussian" Region $\rightarrow$

+Hultiple Scattering $\longleftarrow$ Plural Scattering
0

0

0.0441

0.0456

$+39$

0.0497

0.0441

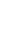

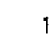

0.0135

0.0133

$-1.58$

0.0150

$6.84(-3)$

$+11.38$

0.0153

0.0197

0.00107

$2.12(-4)$

$+13.08$

$-17.68$

$+22.6$

$+33.5$

$+42.8$

$+26.7$

$+17.48$ 
TABLE IV (cont.), B

Comparisons with Experiment: Hanson et al for $\mathrm{Au}, 0.01866 \mathrm{~g}^{5} \mathrm{~cm}^{2}$, Mean Electron Energy $15.69 \mathrm{MeV}$ Doninant Sall Angle "Gaussian Part"

Parameter

$\checkmark \equiv \theta / W$ Eq. (17)

Scattering Angle, $\theta$

$f(\theta) / 2 \pi \mid$ exper1ment, Eq. (2)

J $\quad 0.554^{\circ} \quad 1.107^{\circ}$

0.0441

0.0422

$0.035 i$

0.6

0.8

1.0

1.2

$\mathrm{r}_{\mathrm{HBM}} / 2 \pi$, Eq. (2)

0.0455

0.0432

0.0374

$2.768^{\circ}$

$3.322^{\circ}$

\$ dirference, HBM:expt.

$\mathrm{f}_{\mathrm{H}} / 2 \pi, E q=(18)$ (Gausglan)

$+3.18$

$+2.48$

$+4.68$

$0.0277 \quad 0.0198$

0.0135

0.00832

0.0497

0.0474

0.0411

$0.0290 \quad 0.0203$

0.0133

0.00817

7 difference, H:expt.

$\mathrm{f}_{\mathrm{I}} / 2 \pi, \mathrm{Eq} \cdot\left(2^{n}\right)$ (Gaussian)

$+12.7 \%$

$+12.4 \%$

$+14.9 \%$

$+4.78+2.68$

$-1.68$

$-1.98$

0.0441

0.0423

0.0372

0.0323

0.0231

0.0150

0.00887

I differerce, I :expt.

$+0.2 \%$

$+4.18$

$+11.3 \%$

$+6.6 \%$

0.0153

0.00956

0.0301

0.0224

$+13.0 \%$

$+14.99$ 
the $1 / e$ width from the Hanson et al approximation discussed in Section IV, and $w_{I}$ is a variant of $w_{H}$, adjusted to match experiment at $\theta=0^{\circ}$, the most probable event, i.e. $f(0) \geq f(\theta)$, except possibly for extreme thicknesses where $\sin \theta-\theta$ is no longer even a fair approximation. $W_{I}$ is discussed in section $V$. It can be seen that the HBM theory widths agree to within 1 to 3\%, usually, with the experimental widths, and the far simpler Hanson approximation widths do just as well. Unfortunately, as we've noted, width matching does not guarantee curve matching, as also we will show below. A measure of the discrepancy is given by the difference of the widths, $W_{I}$, which were derived by settin: a rormalized "Gaussian" equal to $f(0)$. We see that the width error approaches 7-8\% for these widths, whereas the HBM and $\mathrm{H}$ widths generally run to $\leqslant 3 \%$ different than experiment.

Table IV gives a detailed comparison of the theories for one hanson et al 5 target and eriergy, to wit Au of $0.01866 \mathrm{~g} / \mathrm{cm}^{2}$ thickness with $15.7 \mathrm{MeV}$ electrons incident. The first part of Table IV, A, gives an overview far out into the wings to where the distribution has dropped to $2 / 100000$ of the central value. For this case and single scattering, Hanson's (Eq. (21)) simple, large angle expression is best. For multiple and plural scattering the Hanson-Bethe-Molière formulae are clearly superior. The important central region is examined in detail in the second part of Table IV, B. The superior performance of the HBM-theory is evident. The H-theory is quite good and vastly simpler than the HBM-theory. The Mod. I theory is a bit spuriously good here because it was normalized to the Hanjon et a] experiments at $\theta=0$. Use of $\mathrm{Eq}$. ( $(\dot{\mathrm{u}})$ of course gives identical resuits because Eq. (26) was denived to precisely fit the $x$ that gave the $D^{\circ}$ scattering probability for the Hanson et al experiments.

Table $V$ compares the theories with the experiments of Heymann and Jennings, 6 at $4.5 \mathrm{MeV}$ electrons incident. The Table concentrates attention to the high probability region of $\mathscr{N} \leq 2$, which region contains roughly $98 \%$ of the scattered electrons, (for a pure Gaussian, the region contains exactly $\left.\left(1-e^{-4}\right)=98.168 \%\right)$. Out to about $\mathscr{\sim}=1(-63 \%$ of all scattered electrons $)$ the 
Hanson-Bethe-Molière theory is indistinguishable from experiment, to the accuracy with which I can read Heymann and Jennings graphs ( $3 \%$ ?). In the region $\mathscr{V}=1$ to $\mathscr{V}=2,(-35 \%$ of electrons), the HBM theory is good to 10 or $20 \%$. The Hanson et al approximation is good to about $10 \%$ over the entire range $2<1.4$. Amazingly, just the first term of HBM, $\mathrm{f}^{(0)}$ (see Eqs. (2) and (12)) is good to $10 \%$ or less for $\mathscr{F}<2$, clearly superior here to the Hanson Approximation. Matching a normalized "Gaussian" at $\theta=0$ does very well up to $\vartheta=0.6$ but remains superior to the Hanson Approximation throughout. Because the data of Heymann and Jennings were given in terms of $w^{2} f$, we have presented the comparisons that way. From Eq. (2)

$$
\begin{aligned}
& w^{2} f=2 \pi w^{2} d \Sigma / d \Omega . \\
& \% \text { HBM : expt } \equiv 100 \frac{w^{2} f}{w^{2} f_{\operatorname{expt}}-w^{2} f_{\operatorname{expt}}}
\end{aligned}
$$

for example. Again $f_{I}$ is a bit spuriously good because it is normalized to experiment at $\theta=0$. A better test of the general or predictive usefulness of Mod. I is to use Eq. (26) for $x$ rather than Eq. (24). The results are given in Table $V$, labeled $w^{2} f_{I^{*}}$. The results are superior to Hanson but not as good as 3 simple $x=0.6$, for example.

Tabie VI compares the theories with the $2.25 \mathrm{MeV}$ incident measurements $c$ Kulchitsky and Latyshev. 10 Unfortunately, they did not give absolute numbers and numerical integration of their small graphs appeared to be likely inaccurate for reasonable effort. So their results are normalized to the the rries, which of course gives a better agreement than generally warranted. They also give left and right scattering of the electrons. The left and right scattering differences usually exceed their graphed error bars. For Sn, for example, in the angies 16 to $30^{\circ}$ the left right differences are 13 to $50 \%$ where the bars are $s \pm 3 \%$. Nonetheless, we cannot find agreement within 
TABLE V

Comparisons with Experivent: Heyeann and Jennings ${ }^{6}$ for $A 1$ and Pt, 4.5 HeV Eqectrons Incldent

A1, $0.0652 \mathrm{~g} / \mathrm{cos}^{3}, x_{c}=0.0532, \mathrm{~B}=8.44, w-8.855^{\circ}, w_{H}=8.20^{\circ}, w_{I}=8.571 \bullet, x=0.5337$

\begin{tabular}{|c|c|c|c|c|c|c|c|c|c|c|c|}
\hline $\boldsymbol{S} \equiv 0 / W E q .(17)$ & 0 & 0.2 & 0.4 & 0.6 & 0.8 & 1.0 & 1.2 & 1.4 & 1.6 & 1.8 & 2.0 \\
\hline$\theta$, scatt. angle & 0 & $1.771^{\circ}$ & $3.542^{\circ}$ & $5.313^{\circ}$ & $7.084^{\circ}$ & $8.855^{\circ}$ & $10.63^{\circ}$ & $12.40^{\circ}$ & $14.17^{\circ}$ & $15.94^{\circ}$ & $17.71^{\circ}$ \\
\hline$w^{2} f_{\text {expt }} E q .(2)$ & 2.137 & 2.047 & 1.759 & 1.387 & 1.00 & 0.6518 & 0.440 & 0.287 & 0.178 & 0.087 & 0.053 \\
\hline$w^{2} f_{H B M}, E q \cdot$ (2) & 2.135 & 2.034 & 1.777 & 1.400 & 0.999 & 0.6623 & 0.413 & 0.245 & 0.135 & 0.0816 & 0.0477 \\
\hline HBM: expt & 0 & -0.67 & $+1 . \%$ & $+0.9 \%$ & -0.18 & +1.64 & -6.19 & -14.68 & -24.28 & $-6.2 \%$ & -10.7 \\
\hline$w^{2} f^{\langle 0\rangle}{ }_{H B M}, E q$. (2) & 2. & 1.922 & 1.704 & 1.395 & $i .055$ & 0.7358 & 0.4739 & 0.2817 & 0.1546 & 0.07833 & 0.03663 \\
\hline x HBM(o): expt & -6.48 & -6.18 & -3.19 & +0.69 & $+5.5 \%$ & $+12.9 \%$ & $+7.7 \%$ & $-1.8 q$ & -13.19 & $-10.0 \%$ & -23.27 \\
\hline$w^{2} f_{H}, E q \cdot(18)$ & 2.332 & 2.226 & 1.935 & 1.533 & 1.106 & 0.7267 & 0.4345 & 0.2370 & 0.1177 & 0.0533 & 0.02198 \\
\hline I H: expt & +9.19 & $+8.7 \%$ & $+10.0 x$ & $+10.5 \%$ & +10.67 & +11.65 & $-1 \cdot 38$ & -17.48 & -34.8 & -39.8 & -59.8 \\
\hline $\begin{array}{l}\mathrm{w}^{2} \mathrm{C}_{\mathrm{I}}, \mathrm{EQ} \cdot(22) \\
\mathrm{x}=0.5337\end{array}$ & 2.137 & 2.048 & $1.80 \%$ & 1.454 & 1.078 & 0.7342 & 0.4585 & 0.2632 & 0.1388 & $0.0671 \varepsilon$ & 0.02986 \\
\hline I : expt & 0 & 0 & $+2.4 \%$ & +4.87 & $+7.8 \%$ & $+12.6 \%$ & +4.27 & $-8 \cdot 39$ & -22.8 & $-23 . \%$ & -44.7 \\
\hline $\begin{array}{l}w^{2} \mathrm{c}_{\mathrm{I}}^{*}, \text { Eqs. } \\
x=0.6774\end{array}$ & 2.174 & 2.082 & 1.827 & 1.470 & 1.084 & 0.7331 & 0.4539 & 0.2579 & 0.1344 & 0.0642 & 0.0281 \\
\hline $8 I^{*}: \operatorname{expt}$ & $+1.8 x$ & $+1.7 \%$ & $+3.9 \%$ & +6.01 & $+8.4 \%$ & $+12.5 \%$ & +3.28 & $-10.1 \%$ & $-24.5 \%$ & -269 & -479 \\
\hline
\end{tabular}


TABLE V (cont.)

Coparisons with Exper!ment: Heywann and Jenn1ngs 6 , 4.5 HeV Electrons Incldent

$P t, 0.0544 \mathrm{~g} / \mathrm{cm}^{2}, x_{c}=0.1049, B=7.76, w=16.743^{\circ}, v_{H}=15.37^{\circ}, w_{I}=16.148 \%$, II $=0.5413$

\begin{tabular}{|c|c|c|c|c|c|c|c|c|}
\hline $\mathscr{V} \equiv \theta / W E q \cdot(17)$ & 0 & 0.4 & 0.6 & 0.8 & 1.0 & 1.2 & 1.6 & 2.0 \\
\hline e. scattering angle & 0 & $6.697^{\circ}$ & $10.05^{\circ}$ & $13.39^{\circ}$ & $16.743^{\circ}$ & $20.09^{\circ}$ & $26.79^{\circ}$ & $33.49^{\circ}$ \\
\hline$w^{2} f_{\text {expt Eq. }}$ (z) & 2.149 & 1.779 & 1.396 & 1.001 & $0.69 ? 8$ & 0.500 & 0.1439 & not meas \\
\hline$w^{2} f_{H B M}, E q \cdot(2)$ & 2.150 & 1.783 & 1.399 & 0.9932 & 0.6551 & 0.4072 & 0.1406 & 0.04886 \\
\hline$\$$ HBM: expt. & 0 & +0.24 & +0.28 & -0.18 & $-6.1 \%$ & $-18.6 \%$ & $-2.3 \%$ & - \\
\hline$\left.W^{2} f^{(0)}\right)_{B M}$, Eq. (2) & 2 & 1.704 & 1.395 & 1.055 & 0.7358 & 0.4739 & 0.1546 & \\
\hline $\mathrm{HBM}(0): \operatorname{expt}$ & -7.08 & -4.78 & -0.19 & +5.49 & $+5.5 \%$ & $-5.2 \%$ & $+7.4 \%$ & - \\
\hline$w^{2} f_{H}, E q \cdot(18)$ & 2.373 & 1.963 & 1.548 & 1.111 & 0.7247 & 0.4299 & 0.1137 & 0.02058 \\
\hline H:expt & +10.48 & +10.31 & +10.98 & $+11.0 \$$ & +3.98 & -14.08 & -21.8 & - \\
\hline$w^{2} f_{I}, E q \cdot(22), x=0.5413$ & 2.149 & 1.810 & 1.460 & 1.081 & 0.7341 & 0.4574 & 0.1371 & - \\
\hline I : expt & 0 & $+1.7 \%$ & $+4.6 \%$ & $+8.0 \%$ & +5.28 & $-8.5 \%$ & -4.78 & - \\
\hline$w^{2} f_{I}^{*}$, Eqs. $(26),(22), x=0.747$ & 2.213 & $1.85 !$ & 1.485 & 1.091 & 0.7319 & 0.450 & 0.1302 & - \\
\hline $8 I^{*}: \operatorname{expt}$ & $+3.0 \%$ & +4.28 & +6.48 & +9.05 & +4.98 & -10.08 & -9.58 & - \\
\hline
\end{tabular}


TABLE VI

Cooparibons with Experiment: Kulchitsky and Latyshev10 for A1, Sn, and Pb; 2.25 MeV Incident Electron Energy (Hormal ized to HBM at $\sigma=0.8$ or $\sigma^{\circ}=0$ ).

$11,0.0266 \mathrm{~g} / \mathrm{con}^{2}, x_{C}=0.06294, B-7.387, v=9.802^{\circ}, \mathrm{W}_{\mathrm{H}}=8.97^{\circ}$

\begin{tabular}{|c|c|c|c|c|c|c|c|c|c|}
\hline $\begin{array}{l}\sigma \equiv \theta / w, \text { Eq. }(17) \\
\theta, \text { scattering } \\
\text { Angle }\end{array}$ & $\begin{array}{l}0 \\
0\end{array}$ & $\begin{array}{l}0.2 \\
1.96^{\circ}\end{array}$ & $\begin{array}{l}0.4 \\
3.921^{\circ}\end{array}$ & $\begin{array}{l}0.8 \\
7.841^{\circ}\end{array}$ & $\begin{array}{l}1.2 \\
11.76^{\circ}\end{array}$ & $\begin{array}{l}1.6 \\
15.480\end{array}$ & $\begin{array}{l}2.0 \\
19.6 n 0\end{array}$ & $\begin{array}{l}2.4 \\
23.50^{\circ}\end{array}$ & $\begin{array}{l}3.0 \\
: 9.40^{\circ}\end{array}$ \\
\hline$f_{H B M}=2 \pi d \Sigma / d \Omega E q . \quad(2)$ & $2.248(-2)$ & $2.139(-2)$ & $1.86(-2)$ & $1.03(-2)$ & $4.201(-3)$ & $1.459(-3)$ & $5.163(-4)$ & $1.987(-4)$ & $5.731(-7)$ \\
\hline $\begin{aligned} f_{\text {expt }} \text { (normal 1zed to } \\
\mathrm{f}_{\text {HBM }} \boldsymbol{\nabla}=0.8 \text { ) }\end{aligned}$ & $2.157(-2)$ & $2.089(-2)$ & $1.73(-2)$ & $\begin{array}{l}1.03(-2) \\
\text { normal ized }\end{array}$ & $5.053(-3)$ & $\begin{array}{l}1.94(-3) \\
\text { to } 1.64(-3)\end{array}$ & $4.28(-4)$ & $2.55(-4)$ & $8.5(-5)$ \\
\hline I HBM: expt. & $+4.2 \%$ & $+2.4 x$ & +7.51 & $\begin{array}{l}0 \text { (nor- } \\
\text { mal1zed) }\end{array}$ & -16.94 & -25 to -14 t & +218 & -221 & $-33 z$ \\
\hline$f_{H} E q \cdot(18)$ & $2.482(-2)$ & $2.37(-2)$ & $2.053(-2)$ & $1.158(-2)$ & $4.456(-3)$ & $1.17(-3)$ & $2.098(-4)$ & $2.568(-5)$ & $5.37(-7)$ \\
\hline $\begin{array}{l}\text { H (normaldzed to } H_{H B M} \\
N=0.80) \text { :expt. }\end{array}$ & +2.58 & +0.98 & .5 .68 & $\begin{array}{l}\text { (nor- } \\
\text { mal } 1 \text { zed })\end{array}$ & $-22 \%$ & $-47 q$ & $-56 \%$ & -918 & -99.448 \\
\hline
\end{tabular}

$\mathrm{Sn}, 0.0174 \mathrm{~g} / \mathrm{cm}^{2}, x_{C}=0.09083, B=6.791, w=13.561^{\circ}, w_{H}=12.305^{\circ}$

$\mathbf{f}_{\text {HBM }}$

$2.712^{\circ} \quad 5.424^{\circ}$

$10.85^{\circ}$

$16.27^{\circ}$

$21.70^{\circ}$

$27.10^{\circ}$

$32.55^{\circ}$

fexpt (normalized to HBM 0 )

$1.183(-2)$

$1.126(-2)$

$9.759(-3) \quad 5.344(-3)$

$2.158(-3)$

$7.575(-4)$

$2.772(-4)$

$1.095(-4)$

normallzed

3.85
$(-3)$

$4.3-4.88$

$1.38-2$.

6. $88(-5)$

8) HBM: expt

0 (nor-

$(-3)$

$(-4)$

tn $1.032(-4)$

$f_{H}$

$1.3209(-2)$

76 to $55 \%$

+100 to 398

+59 to 6.18

0 (normallzed)

1. $258(-2) \quad 1.080(-2) \quad 6.07(-3)$

$2.299(-3)$

$5.89(-4)$

$1.026(-4)$

$1.208(-5)$

(normal1zed to HBM (e) : expt.

$+3.29$

$+7.98$

+41 to $24 \%+63$ to $44 \%$

+23 to $8.15-33$ to -548

-84 to $-90 \%$ 


\section{Table VI (cont.)}

Comparisons with Experiment: YulchItsky and Latyshev, 102.25 MeV Electrons

$\mathrm{Pb}, 0.0079 \mathrm{~g} / \mathrm{cm}^{2}, x_{\mathrm{C}}=0.075676, \mathrm{~B}-5.450, w-10.122^{\circ}, \mathrm{v}_{H}=8.939^{\circ}$

\begin{tabular}{|c|c|c|c|c|c|c|c|c|c|}
\hline$N^{\prime} \equiv \theta / W, E q .(17)$ & 0 & 0.2 & 0.4 & 0.8 & 1. & 1.6 & 2.0 & 2.4 & 3.0 \\
\hline B, Scattertng Angle & 0 & $2.024^{\circ}$ & $4.049^{\circ}$ & $8.098^{\circ}$ & $12.15^{\circ}$ & $16.20^{\circ}$ & $20.24^{\circ}$ & $24.29^{\circ}$ & $30.37^{\circ}$ \\
\hline$f_{\mathrm{HBM}}=2 \pi \mathrm{d} \Sigma / \mathrm{d} \Omega$, Eq. $(2)$ & $2.185(-2)$ & $2.069(-2)$ & $1.776(-2)$ & $9.38(-3)$ & $3.668(-3)$ & $1.338(-3)$ & $5.405(-4)$ & $2.266(-4)$ & $7.22(-5)$ \\
\hline $\begin{array}{l}\text { fexpt (normallzed to } \\
f_{\text {HBM }} \nabla=0.8 \text { ) }\end{array}$ & $1.86)(-2)$ & $1.815(-2)$ & $1.54(-2)$ & $\begin{array}{l}9.39(-3) \\
\text { normal1zed }\end{array}$ & $4.12(-3)$ & $1.754(-3)$ & $7.63(-4)$ & $3.05(-4)$ & $9.08(-5)$ \\
\hline SHBM: expt. & $+17.4 \%$ & +14.5 & +15.39 & $\begin{array}{c}0 \\
\text { normalfzed }\end{array}$ & $-9.7 \%$ & -24.8 & -29.8 & -26.8 & -21.1 \\
\hline $\mathbf{f}_{H}$, Eq. $(18)$ & $2.503(-2)$ & $2.378(-2)$ & $2.039(-2)$ & $1.102(-2)$ & $3.946(-3)$ & $4.38(-4)$ & $1.49(-4)$ & $1.56(-5)$ & $2.43(-7)$ \\
\hline $\begin{array}{l}\text { S H (normalized to HВM } \mathrm{e} \\
\vartheta=0.8 \text { ) expt. }\end{array}$ & $+14.5 \%$ & +11.56 & +12.75 & $\begin{array}{c}0 \\
\text { normall zed }\end{array}$ & $-18.5 \%$ & -54.8 & -83.8 & -95.78 & $-99.77 \%$ \\
\hline
\end{tabular}


experimental error with either the HBM or the $H$ theories above $\mathscr{V}=1$ for $S n$. For $\mathrm{Al}$ and $\mathrm{Pb}$ and for $\mathrm{Sn} \mathscr{S} \leq 1$ the theories agree with experiment as far as we can tell from the relative measurements, i.e. the shape is proper. But our determingtions are no better than say 4 to $17 \%$ to $26 \%$ in these regions. Thus Kulchitsky and Latyshev gives us a very weak check indeed on the theory. As before

$$
q_{H}: \operatorname{expt} \equiv 100 \cdot \frac{\mathrm{f}_{\mathrm{H}}-\mathrm{f}_{\text {expt }}}{\mathrm{f}_{\text {expt }}} \text {. }
$$

\section{CONCLUSIONS, RECOMMENDATIONS}

The scope of the experiments known to this writer is limited to thicknesses relative to energy where multiple scattering clearly dominates. The experiments are also for the most part restricted to small angle scattering. In the one case 10 where I can independently check experimental error, the error is much worse than the author's error bars indicate. As a consequence: 1) we have no way of testing the 1 imits of the theory; and 2) the accuracy of the experiments is suspect. One case, certainly, does not establish the latter, but we are also disturbed to find, upon calculation, that often the claimed theory to experiment agreement is sometimes not substantiated by the numbers. A frequent annoyance is the misrepresentation of the theories used, e.g. Only the first term of the Molière theory represented as the full Molière theory. I estimate that experimental accuracy could be better than 5\%, but could also be (and is) worse (especially at large but not very probable angles) than $50 \%$ in acciuracy. One shculc bear these numbers in mind and our uncertainty in knowing them when deciding upon the merits of the theories. Exceptions to this gloomy picture are the $1 / \mathrm{e}$ widths. These, it would appear, are accurate to a few percent. See, for example, Table III.

For the best theory of the electron angular distributions, we recommend the Hanson-Bethe-Moliere Theory, (HBM Theory), of Eqs. (2), (4), (5), (6), (7), (8), (9) or $(10),(11),(12),(13)$, and $(14)$; or Table I. Its 
limitations are described in the beginning of section III. Its drawback is the complication of the expressions (13) and (14). It, itself, is an approximation, alleged improper by Nigam, Sundaresan, and Wu. 9 Its advantage is that it is the most tested against what experiment we have, and it fits experiment very well indeed in the high probability central region, but is only fair at the large angles (but which have low probability). See Tables IV, V, and VI. Also it possesses the proper limits at large (but $\leq 30^{\circ}$ ) angles and at small thicknesses and has a theoretical basis, if only approximate, so that one has more confidence in it outside of the tested regimes.

If only the $1 / \mathrm{e}$ width in the multiple scattering regime is desired, the Hanson et al 5 suggestion Eqs. $(20),(5),(6),(7),(8)$, and (9) or (10) is fully as good as HBM, sometimes better, and vastly simpler. For the best widths of multiple scattering it is recommended.

Use of the Hanson et al width, $w_{H}$, in a normalized "Grissian," Eq. (18), is a simple and fairly accurate ( - 10\% error) approximation good up to about $\boldsymbol{N}=1.2$ which includes $-75 \%$ of the probability. Above $\boldsymbol{N}=1.2$ the approximation is much too low. For plural and single scattering, therefore, one must add terms, i.e. for single scattering, Eq. (21) or (27). We have no plural scattering correction to the Hanson approximation. The Hanson Gaussian approximation by itself contains all the probability, i.e. 100\%, but concentrates it somewhat in the small angles, $\boldsymbol{F} \leqslant 1$, in order to give an accurace 1/e width. Consequently, the approximation is low at higher angles, very low in the single scattering regime.

The comparisons of Tables IV, V, and VI show that the Hanson choice of $x=1.2$ in Eq. (20) or (25) does not do as well as a smaller value for $x$ in representing $f$ or $d \tau / d \sigma$ uver a range of angles, $\theta$. Acco:dingly, a simple approximation, more accurate than Hanson except for the $1 / \mathrm{e}$ widths, is to put $x=0.6$ in Eq. (25) and use Eq. (22) which will give the dominant multiple scattering. $x_{c}$ and $B$ are given by Eqs. $(5),(6),(7),(8)$, and $(9)$ or $(10)$. We recommend this procedure for its simplicity and good accuracy, (s $\sim 10 \%$ for $\left.\theta \leq x_{C} \sqrt{B}\right)$. We find, for the data known to us, that using Eq. (2f) for $x$ in place of $x=0.6$ is generally a little better yet, especially for small angles 
for which it was designed. It adds the evaluation of the expression (26), however. It, that is Ens. (26), (25), and (22), is recommended as the best simple multiple scattering formula.

To the foregcing, one may add either the single scattering of Eq. (21) or that of Eq. (27). Neither is satisfactory; both omit plural scattering largely. Eq. (21) is simpler. Eq. (27) can be carried out to angles $\theta \geq 30^{\circ}$, but not to $90^{\circ}$ for a wide slab. See the discussion in Modification II, Section $V$. One could adjust these equations ((20) and (27)) to fit better any given data. To do so with any confidence of giving accurately an unmeasured distribution would require research not yet in evidence in the literature. These additions slightly increase the total probability over 1, (provided by the Gaussian normalization). The HBM theory is strictly normalized in its entiroty, term by term, (the first being 1 the rest 0 ).

We remind the user that no correction for electron energy loss has been included in this paper. Small loss can be compensated for by using the mean electron energy in the slab, rather than the incident energy. The mean energy may be determined from electron energy loss tables. Considerable loss requires integration of the scattering over the slab thickness.

\section{FUTURE NEEDS}

The field of electron scattering needs wide ranging experiments determined to accuracies at least approaching $1 \%$ although even wp to $10 \%$ is still useful. The angular distribution results should be absolute, i.e. normalized to unit probability, and clearly presented to facilitate numerical comparisons. With a decent sampling: of thick to thin targets, of the energy range, and of the periodic table, one is then in the position to check the various theories to find the best and simplest, and also to provide simple empirical formulas that can give good accuracy without undue algebraic labor.

But without experiment, nothing is sure. 


\section{ACKNONLEDGBMENTS}

It is a pleasure to acknowledge conversations with and references from: Joseph Mack and $W$. L. Thompson of $X-6$, Les Thode, $X-8$, and from N. Jarmie of P-3; and a reference clarification by Frof. A. 0 . Hanson of the Univ. of 11 nois at Urbana-Champaign.

\section{REFERENCES}

1. W. T. Scott, "The Theory of Small-Angle Multiple Scattering of Fast Charged Particles," Rev. Mod. Phys. 35, 231, (1963).

2. G. Molière, "Theorie der Streuung schneller geladener Teilchen I and II," Z. Naturf. 2a, 133 (1947) and 3a, 78 (1948). The latter, treating plural and multiple scattering, is avallable in English translation by Associated Technical Services in the U.S. Atomic Energy Report, (now DOE), AEC-tr-2119.

3. H. A. Bethe, "Molière's Theory of Multiple Scattering," Phys. Rev., 89, 1256 (1953). The first term of Eq. (29) should be multiplied by 1/4. (Refer to Molière Ref. 4). Table II, last column should read; $0,00166,0.01343,-0.000285,-0.1246, \cdots$.

4. N. F. Mott and H.S. W. Massey, The Theory of Atomic Collisions, 3rd ed, clarendon Press, (Oxford, 1965) p. $4 \overline{7} 4$.

5. A. O. Hanson, L. H. Lanzl. E. M. Lyman, and M.B. Scott, "Measurement of Multiple Scattering of 15.7 MeV Electrons," Phys. Rev., 84, 634 (1951).

6. F. F. Heymann and R. E. Jennings, "The Multiple Scattering of $4.5 \mathrm{MeV}$ Electrons," Proc. Roy. Soc., A234, 116 (1956).

7. S. Coudsmit and J. L. Saunderson, "Multiple Scattering of Electrons," Phys. Rev, 57, 24 (1940) and 58, 36 (1940).

8. E. Breitenberger, "Theory of Multiple Scattering," Proc. Roy. Soc., A250, $514(1959)$.

9. B. P. Nigam, M. K. Sundaresan, and T. Wu, "Theory of Multiple Scattering: Second Born Approximation and Corrections to Molière's Work, "Phys. Rev., 115, 491 (1959).

10. L. A. Kulchitsky and G. D. Latyshev, "The Multiple Scattering of Fast Electrons," Phys. Rev., 61, 254 (194?). 
A. I. Andrievsky, L. A. Kulchitsky, and G. D. Latyshev, "Multiple Scattering of East Electrons. II," Sov. J. Phys. 6. 278 (1942) (English translation).

11. J. H. Jacob. "Multiple Electron Scattering through a Slab," Phys. Rev. A8, $226(1973)$.

12. S. Kageyama, "The Multiple Scattering of Fast Electrons," J. Phys. Soc. Jap. 11348 (1956). Kageyama actually tests only against the f'irst term of the HBM theory and against Hanson's Approximation. I have estimated that the good agreement of the latter also follows ior the full HBM theory for $\theta$ small.

13. H. Bichsel, "Multiple Scattering of Protons," Phys. Rev., 112, 182 (1958).

14. R. F. Mozley, R. C. Smith, and R. E. Taylor, "Multiple Scattering of 600-MeV Electrons in Thin Foils," Phys. Rev., 111, 64"' (1958).

\section{BIBLIOGRAPHY}

1. J. B. Marion and B. A. Zimmerman, "Multiple Scattering of Charged Parti-cles," Nucl. Inst. Meth., 51, 93 (1967).

J. B. Marion and F. C. Young, Nuclear Reaction Analysis, North-Holland, (Amsterdam, 1968) p. 30.

2. H. Bichsel, "Multiple Scattering of Protons," Phys. Rev., 112, 182 (1958).

3. 4. I. Andrievsky, L. A. Kulchitsky, and G. D. Latyshev, Sov. $\therefore$ Fhys., 占. $278(1942)$.

4. J. E. Draper, "Mu?tiple Scattering - A Different Approach for any Cross Section and any Scatterer Thickness," Nucl. Inst. Meth. 190, 181 (1981).

* Work of the early 60's and before will be found in scott's review article above (Ref. 1). 
5. R. M. Sternheimer in L. C. L. Yuan and C. Wu, Eds. Nuclear Physics Vol. 5, Part A, Academic (New York, 1961) p. 73.

6. E. Breitenberger, Proc. Roy. Soc., A250, 514 (1959).

7. S. Goudsmit and J. L. Saunderson, "Multiple Scattering of Electrons," Phys. Rev., 57, 24 (1940) and Phys. Rev. 58, 36 (1940).

8. 0. Knecht u. W. Bothe, "Vielfachstreuung Schneller Elektronen," Z. Nat. 8a, 805 (1953).

9. J. S. Goldberg, H. S. Snyder, and W. T. Scott, "Mean-Value Calculations for Spatial Multiple Scattering," Phys. Rev., 100, 1013 (1955).

10. W. T. Scott, "Mean-Value Calculations for Projected Multiple Scattering," Phys. Rev., 85, 245 (1952).

11. E. M. Lyman, A. O. Hanson, and M. B. Scott, "Scattering of $15.7 \mathrm{MeV}$ Electrons by Nuclei," Prys. Rev. 84, 626 (1951).

12. B. P. Nigam and V. S. Mathur, "Difference in the Multiple Scattering of Electrons and Positrons," Phys. Rev. 121, 1577 (1961).

13. A. A. Bednyakov et al, "Multiple Scattering of Nitrogen and 0xygen in Aluminum," Sov. Phys. JETP, 23, 391 (1966).

14. M. L. Ter-Mikaelyan, "Theory of Multiple Scattering," Sov. Phys. JETP, 36, 171 (1959), also Nucl. Phys. 9, 679 (1958/9).

15. E. Hisdal, "Bremsstrahlung Spectra Corrected for Multiple Scattering in the Target," Phys. Rev. 105, 1821 (1957).

16. H. Daniel, "Multiple Scattering in a Magnetic Field," Nucl. Inst. Meth., 124, 253 (1975).

17. A. Z. Dolginov and V. N. Gnedin, "Multiple Scattering," Nucl. Phys. 53, $371(1964)$, 77, $202(1966)$, and Sov. Phys. JETP 27, 267 (1968).

18. E. V. Hungerford et al, "Proton Multiple Scattering at $600 \mathrm{MeV}$," Nucl. Phys., A197, 515 (1972).

19. P. C. Hemmer and I. E. Farquhar, "Multiple Scattering," Phys. Rev. 168, 294 (1968).

20. H. S. Snyder and W. T. Scott, "Multiple Scattering of Fast Charged Particles," Phys. Rev. 76, 220 (1949). 
21. L. E. Thode, "Preliminary Investigation of Anamolous Relativistic Electron Beam Deposition into a $10^{17}$ to $10^{20} \mathrm{~cm}^{-3}$ Density Plasma," Los Alamos Scientific Laboratory report LA-7215-MS, (April 1978).

22. R. D. Birkhof $f$ in S. Flügger, Ed., Handbuch der Physik, Vol. 34 , Korpuskeln u. Strahlung in Materie II, Springer (Berlin, 1958) pp 115 to 121.

23. N. F. Mott and H. S. W. Massey, Atomic Collisions, 3rd Ed., Clarendon Press, (Oxford, 1965) pp. 467-475.

24. H. A. Bethe and J. Ashkin in E. Segré, Ed., Experimental Nuclear Physics John Wiley, (New York, 1953) pp. 282-292.

25. H. Bichsel in D. E. Gray, Ed., American Institute of Physics Handbook, 3rd Ed., McGraw-Hill, (New York, 1972) pp. 8-176 to 8-179. 